\title{
WT1 shRNA delivery using transferrin-conjugated PEG liposomes in an in vivo model of melanoma
}

\author{
SANTIAGO SAAVEDRA-ALONSO ${ }^{1}$, PABLO ZAPATA-BENAVIDES ${ }^{1}$, ANA KARINA CHAVEZ-ESCAMILLA ${ }^{1}$, \\ EDGAR MANILLA-MUÑOZ ${ }^{1}$, DIANA ELISA ZAMORA-AVILA ${ }^{2}$, \\ MOISÉS ARMIDES FRANCO-MOLINA ${ }^{1}$ and CRISTINA RODRIGUEZ-PADILLA ${ }^{1}$
}

\author{
${ }^{1}$ Department of Microbiology and Immunology, Faculty of Biological Sciences, Autonomous University of \\ Nuevo León (UANL), San Nicolás de los Garza, Nuevo León; \\ ${ }^{2}$ Department of Genetics, Veterinary Medicine Faculty, Autonomous University of \\ Nuevo León (UANL), Escobedo, Nuevo León, México
}

Received January 13, 2016; Accepted May 31, 2016

DOI: $10.3892 / \mathrm{etm} .2016 .3851$

\begin{abstract}
The global incidence of melanoma is increasing. Mortality from melanoma is influenced primarily by metastasis in advanced stages of the disease. Current treatments are largely ineffective; thus, novel gene delivery approaches that target tumor-specific markers may be useful for the treatment of melanoma. Systemic administration of encapsulated RNA-interference plasmids targeted against tumor cells is a potential alternative therapy for cancer. Formulations of transferrin (Tf)-conjugated polyethylene glycol (PEG) liposomes loaded with short hairpin RNA (shRNA) against $W T 1$ (Lip + RNAi + Tf), PEG liposomes loaded with shRNA against $W T 1$ (Lip + RNAi), Tf-conjugated PEG liposomes loaded with pEGFP-N3 (Lip + GFP + Tf) and saline solution as negative control (untreated) were administered systemically to C57BL/6 mice implanted subcutaneously with a melanoma cell line. Tumor volume, body weight, tumor weight, survival and relative expression of $W T 1$ were evaluated. No significant differences in net body weight were identified between groups. The tumor volume decreased from $7,871 \mathrm{~mm}^{3}(\mathrm{SD} \pm 2,087)$ in the untreated group to $5,981 \mathrm{~mm}^{3}$ $(\mathrm{SD} \pm 2,099)$ in the Lip + RNAi + Tf group. The tumor weight was reduced, from $8.8 \mathrm{~g}(\mathrm{SD} \pm 0.30)$ in the untreated group to $5.5 \mathrm{~g}(\mathrm{SD} \pm 0.87)$ in the Lip + RNAi + Tf group. An increase of $37 \%$ in survival was also observed in the group treated with Lip + RNAi + Tf in comparison to the untreated group. Tumors treated with Lip + RNAi + Tf also showed a decrease in the mean relative expression of WT1 of $0.21(\mathrm{SD} \pm 0.28)$
\end{abstract}

Correspondence to: Dr Santiago Saavedra-Alonso, Department of Microbiology and Immunology, Faculty of Biological Sciences, Autonomous University of Nuevo León (UANL), Unit C, Pedro de Alba S/N, San Nicolás de los Garza, Nuevo León 66450, México E-mail: saas100682@hotmail.com

Key words: transferrin-targeted liposome, WT1, melanoma, RNA interference folds compared with 1.8 ( $\mathrm{SD} \pm 2.49$ ) folds in untreated group, $1.34(\mathrm{SD} \pm 0.43)$ folds in Lip + RNAi group and of 1.89 $(\mathrm{SD} \pm 0.69)$ folds in Lip + GFP + Tf group. Systemic administration of transferrin-conjugated PEG liposomes loaded with shRNA against $W T 1$ reduced WT1 expression and tumor size and increased survival.

\section{Introduction}

Melanoma originates in pigmented melanocytes derived from neural crest cells that are normally present in the epidermis and dermis (1). Melanoma represents $<5 \%$ of skin tumors but carries the greatest mortality rate of all skin neoplasms (2). The global incidence of melanoma has increased markedly (3). Melanoma is able to metastasize through the hematogenous or lymphatic system $(4,5)$. Advanced-stage, metastatic disease confers a poor prognosis, with a median survival of less than one year $(3,6)$.

The Wilms tumor 1 (WT1) protein is a transcription factor that regulates the expression of genes involved in cell proliferation and apoptosis (7-11). WT1 expression is essential for genitourinary development, and $\sim 10 \%$ of nephroblastomas exhibit WT1 mutations (12). By contrast, wild-type WT1 is overexpressed in a variety of neoplasms, including lung, breast, thyroid and melanoma (13-17).

WT1 is expressed in $>80 \%$ of malignant melanoma cells, but is not present in vivo in normal skin or benign melanocytic nevi (17). Expression of WT1 is associated with melanoma cell proliferation and is a possible marker of melanocytic invasion into the dermis $(18,19)$. In vitro knockdown of WT1 induces apoptosis and increases sensitivity to chemotherapy in B16F10 melanoma cells. Furthermore, in vivo WT1 short hairpin RNA (shRNA) applied by aerosol reduces the number and size of tumors $(20,21)$.

Gene therapy using tumor-targeted liposomes as delivery systems has opened a new era in cancer treatment (22). Liposomes are essentially phospholipid bilayer envelopes capable of systemically delivering drugs or genetic material. The advantage of using phospholipids for systemic delivery is that they are biodegradable, minimally toxic and easily 
removed $(23,24)$. Recent studies show that the addition of polyethylene glycol (PEG) to phospholipids increases the half-life of liposomes in circulation; this modification also improves the ability to incorporate ligand molecules that specifically recognize superficial tumor targets (25-27).

Transferrin (Tf), a glycoprotein required for cellular absorption of iron, is often used in gene or drug delivery systems (28-37). As the Tf receptor (CD71) is overexpressed on the surface of cancer cells, it is a useful target for the delivery of therapeutic agents such as small-molecule drugs and nucleic acids (26,31,37-40).

The aim of the present study was to analyze the antitumor effects of Tf-conjugated PEG liposomes loaded with WTI shRNA applied systemically to a subcutaneous model of melanoma in C57BL/6 mice.

\section{Materials and methods}

Materials. One-palmitoyl-2-oleoyl-sn-glycerol-3-phosphocholine (POPC), dimethyldioctadecyl ammonium bromide (DDAB), pegylated distearoylphosphatidylethanolamine (DSPE-PEG 2000) and DSPE-PEG 2000 conjugated to maleimide were purchased from Avanti Polar Lipids, Inc. (Alabaster, AL, USA). DNase I was purchased from Sigma-Aldrich (St. Louis, MO, USA). Polycarbonate membranes of $100 \mathrm{~nm}$ were purchased from Whatman International, Ltd. (Maidstone, UK). Amicon Centriprep (molecular weight cut-off, $30 \mathrm{kDa}$ ) concentrator was purchased from EMD Millipore (Billerica, MA, USA). Holo-transferrin and 2-iminothiolane hydrochloride (Traut's reagent) were purchased from Sigma-Aldrich. WT1.1 DNA plasmid construction was performed as described by Zamora-Avila et al (20). B16F10 murine melanoma cells were obtained from American Type Culture Collection (ATCC; Manassas, VA, USA). Rat anti-mouse CD71-(FITC) antibody clone $\mathrm{C} 2$ was purchased from BD Biosciences (San Jose, CA, USA). The pEGFP-N3 vector that expressed GFP protein was obtained from Clontech Laboratories, Inc. (Mountain View, CA, USA). Anti-WT1 F6 antibody (sc-7385) was purchased from Santa Cruz Biotechnology, Inc. (Santa Cruz, CA, USA). Anti-glyceraldehyde-3-phosphate dehydrogenase (GAPDH; SAB2500451-100UG) antibody was purchased from Sigma-Aldrich. Anti-goat secondary antibody (\#170-6515) was purchased from Bio-Rad Laboratories, Inc. (Hercules, CA, USA), and anti-mouse secondary antibody (sc-516086) was purchased from Santa Cruz Biotechnology, Inc.

Construction of WT1 shRNA plasmid. WT1 RNAi was designed using siRNA design software available online (Ambion; Thermo Fisher Scientific, Inc., Austin, TX, USA), and synthesized at $0.05 \mathrm{mg}$ (Ambion; Thermo Fisher Scientific, Inc.) to create one recombinant plasmid (named WT1-1). Oligonucleotides for the WT1-1 plasmid were 5'-GATCCG GCTGTCCCACTTACAGATGGAAGCTTGCATCTGTAA GTGGGACAGCTTTTTTGGAAG-3' and 3'-GCCGACAGG GTGAATGTCTACCTTCGAACGTAGACATTCACCCTG TCGAAAAAACCTTCGCCGG-5'. The oligonucleotides were resuspended to a final concentration of $1 \mathrm{mg} / \mathrm{ml}$ and annealed and ligated into pGSH1-GFP (Gene Therapy Systems, Inc., San Diego, CA, USA).
Western blot analysis. Tumoral tissue samples (25 mg) were lysed with TRIzol reagent according to manufacturer's instructions (Thermo Fisher Scientific, Inc., Gaithersburg, MD, USA). Protein concentration was determined using a DC protein assay kit. Proteins (50 $\mu \mathrm{g}$ whole-cell lysates) was electrophoresed on $12 \%$ SDS-polyacrylamide gels and transferred to nitrocellulose membranes (Bio-Rad Laboratories, Inc., Hercules, CA, USA). Blocking was realized with 5\% lactose-free milk and Tween 20 in incubation for $1 \mathrm{~h}$. Three washes were performed after each hybridizing with the above antibodies. Monoclonal anti-WT1 F6 was used at a dilution of 1:2,500 in Tris-buffered saline (TBS) buffer, and secondary antibody was used at 1:5,000 in TBS buffer. To control for protein loading, anti-GAPDH was used at 1:10,000 in phosphate-buffered saline (PBS), and anti-goat secondary antibody was used at 1:5,000. All antibody incubations were $90 \mathrm{~min}$ at room temperature. Protein bands were visualized by enhanced chemiluminescence using Lumi-Light Western blotting substrate Roche Diagnostics (Indianapolis, IN, USA)

Flow cytometric analysis. B16F10 melanoma cells $\left(1 \times 10^{6}\right)$ were resuspended in $200 \mu \mathrm{l}$ PBS buffer and stained with anti-mouse CD71 (FITC) antibody. Cells were then incubated at $4^{\circ} \mathrm{C}$ for $30 \mathrm{~min}$ and spun at $400 \mathrm{x}$ g for $10 \mathrm{~min}$ at $4^{\circ} \mathrm{C}$. Cells were then washed twice with PBS buffer and spun at $1,600 \mathrm{rpm}$ for $10 \mathrm{~min}$ at $4^{\circ} \mathrm{C}$. Cells were suspended in $200 \mu \mathrm{l}$ PBS and analyzed using a Accuri C6 flow cytometer (BD Biosciences) to assess cellular expression of CD71.

Liposomal preparation. Liposomal formulation was performed according to Shi and Pardridge (41). POPC (19.2 $\mu \mathrm{mol})$, DDAB $(0.2 \mu \mathrm{mol})$, DSPE-PEG $2000(0.6 \mu \mathrm{mol})$, and DSPE-PEG 2000-maleimide (30 nmol) were dissolved in a mixture of chloroform/methanol (2:1 in a total volume of $3 \mathrm{ml}$ ) and subsequently evaporated using nitrogen gas. Lipids were then suspended in $0.2 \mathrm{ml}$ PBS buffer containing $200 \mu \mathrm{g}$ plasmid DNA and vortexed vigorously for $2 \mathrm{~min}$. The liposome/DNA suspension was frozen in ethanol/dry ice for $4 \mathrm{~min}$ and thawed at $40^{\circ} \mathrm{C}$ for $2 \mathrm{~min}$ in a cycle 10 times. Adjustments to the size of the liposomes were performed using polycarbonate membranes containing a $100-\mathrm{nm}$ pore size; this step was repeated five times. After extrusion, the liposomes were graduated to $2 \mathrm{ml}$ and stored in the dark at $4^{\circ} \mathrm{C}$. To remove unincorporated DNA inside the liposome, $5 \mathrm{U}$ endonuclease $\mathrm{I}$ and $5 \mathrm{mM} \mathrm{MgCl}_{2}$ were added to the mixture and incubated for $1 \mathrm{~h}$ at $37^{\circ} \mathrm{C}$. DNA concentration was calculated at $\sim 50$ and $60 \%$ using NanoDrop 2000 (Thermo Fisher Scientific, Inc., Waltham, MA, USA).

Anchoring of the protein to liposome was performed using $10 \mathrm{nmol} \mathrm{Tf}$ protein (Sigma-Aldrich) and thiolated using $400 \mu \mathrm{mol} 2$-iminothiolane (Traut's reagent) in $100 \mu \mathrm{l}$ borate-EDTA buffer, $\mathrm{pH} 8.5$ (0.15 $\mathrm{M}$ sodium borate and $0.1 \mathrm{mM}$ EDTA). The mixture was incubated for $2 \mathrm{~h}$ in the dark at room temperature with shaking. Loaded Tf was washed with PBS in a concentration column (Centricon 30; Amicon) and concentrated to a final volume of $0.2 \mathrm{ml}$. The loaded Tf was immediately added to the liposomes and incubated for $24 \mathrm{~h}$ at $4^{\circ} \mathrm{C}$ to allow reaction of the maleimide group to generate PEG-immunoliposome complexes. The 
complexes were dialyzed using an 50-nm membrane to exclude non-incorporated materials. The mean vesicle diameters were determined using a Zetasizer Nano ZS90 particle size analyzer (Malvern Instruments, Ltd., Malvern, UK).

Subcutaneous in vivo model of melanoma. Female C57BL/6 mice (age, 7-8 weeks; weight, 20-25 g) were obtained from Harlan Laboratories S.A. De C.V. (Distrito Federal, Mexico). Seven mice in each group were used in the assay. Animals were housed under a 12-h light/dark cycle and received an autoclaved rodent diet and water ad libitum. All experiments were performed with prior approval from the local animal ethics committee. Four groups of seven mice were used for the in vivo assay. A subcutaneous model of melanoma was developed using the B16F10 cell line (CRL-6475; ATCC), which is derived from the same mouse species. A suspension of $200 \mu \mathrm{l}$ containing $5 \times 10^{5}$ cells was subcutaneously injected into the posterior right flank of the mouse. Complete complex of Tf-conjugated PEG liposomes $(50 \mu 1)$ were loaded with shRNA against WT1 (Lip + RNAi + Tf), PEG liposomes $(50 \mu \mathrm{l})$ and loaded with shRNA against WT1 (Lip + RNAi), Tf-conjugated PEG liposomes $(50 \mu \mathrm{l})$ and loaded with pEGFP-N3 vector (Lip + GFP + Tf) and saline solution (50 $\mu \mathrm{l}$; untreated group) were delivered intravenously through the tail vein on day 4 and every 5 days subsequently until day 29. Surviving mice were sacrificed on day 30 by cervical dislocation according the good management practices guidelines of laboratory animals, and tumors were collected for further analyses. Mouse weight, tumor weight and date of death were recorded.

$R N A$ isolation and reverse transcription-quantitative polymerase chain reaction ( $R T-q P C R)$. Total RNA was isolated from $25 \mathrm{mg}$ tumoral tissue using $1 \mathrm{ml}$ TRIzol according to manufacturer's instructions. The cDNA samples were obtained using $5 \mu \mathrm{g}$ total RNA, $200 \mathrm{U}$ Superscript III and $0.5 \mu \mathrm{g}$ oligo $\mathrm{dT}(12-17)$ at $42^{\circ} \mathrm{C}$ for $90 \mathrm{~min}$, followed by heating at $70^{\circ} \mathrm{C}$ for $10 \mathrm{~min}$. TaqMan ${ }^{\circledR}$ One-Step RT-PCR Master Mix Reagents Kit manufactured by Applied Biosystems (Thermo Fisher Scientific, Inc., Foster City, CA, USA).

Each qPCR reaction was performed with $2 \mu \mathrm{l}$ cDNA and WT1 forward primer, TCTGCGGAGCCCAATACAG, reverse primer, CACATCCTGAATGCCTCTGAAGA, and probe FAM-CACCGTGCGTGTGTATT-NFQ. As an endogenous control, a mouse $\beta$-actin primer set was used, manufactured by Applied Biosystems. For each reaction, we used Universal PCR Master Mix manufactured by Roche Molecular Systems, Inc. (Branchburg, NJ, USA). The protocol was performed for 40 cycles at $94^{\circ} \mathrm{C}$ for $30 \mathrm{sec}$ and $64^{\circ} \mathrm{C}$ for $30 \mathrm{sec}$ using a Real-Time Thermal cycler CROMO4 (Bio-Rad Laboratories, Inc.). Relative quantification was performed using the Livak method (42). All samples were run in duplicate, destilled water was including as negative control of reacction.

Statistical analysis. Significance of different treatments was determined by analysis of variance by Dunnett's test. To survival rate were performed Kaplan-Meier curves, using SPSS software, version 13 (SPSS, Inc., Chicago, IL, USA) All data are expressed as the mean \pm the standard errors of

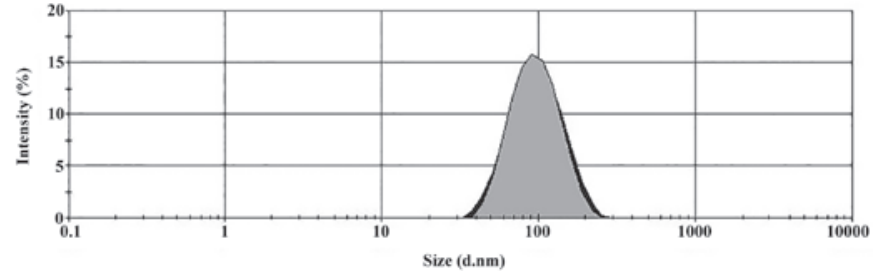

Figure 1. Size distribution according to intensity of liposomes. Approximately $50 \mu \mathrm{l}$ complex was suspended in $1 \mathrm{ml}$ phosphate-buffered saline and analyzed using a Zetasizer Nano ZS90. Mean diameters of Tf-conjugated PEG liposomes loaded with shRNA against WT1 were of $86 \mathrm{~nm}$ and 0.154 of poly-dispersity index.
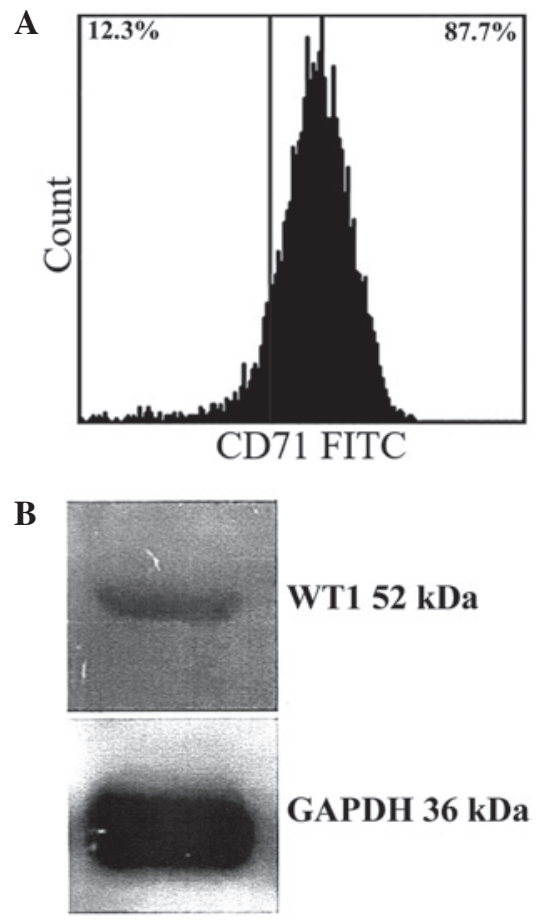

Figure 2. Presence of transferrin receptor and WT1 protein in $\mathrm{B} 16 \mathrm{~F} 10$ melanoma cells. (A) $1 \times 10^{6} \mathrm{~B} 16 \mathrm{~F} 10$ cells were incubated with anti-mouse CD71 antibody, then analyzed using flow cytometry. The figure shows the percentage of positivity to FITC dye. (B) $50 \mu \mathrm{g}$ total protein extraction of $\mathrm{B} 16 \mathrm{~F} 10$ were analyzed using western blot analysis. The figure shows proteins of 52-54 kDa WT1, and the endogenous control GAPDH.

the mean. $\mathrm{P}<0.05$ was considered to indicate a statistically significant difference.

\section{Results}

Size distribution according to intensity of liposomes. Sizes of the Tf-conjugated PEG liposomes loaded with WT1 shRNA are shown in Fig. 1. The mean diameter of the PEGylated Tf-conjugated PEG liposomes loaded with shRNA against $W T 1$ was $86 \mathrm{~nm}$. The poly-dispersity index (PDI) was 0.154 , indicating that the vesicles have a high level of homogeneity. Liposome formulation by vortexing and repeated cycles of freezing-thawing allowed the formation of unilamellar liposomes. Liposomes contained a high concentration of the neutral phospholipid POPC and a minor quantity of cationic lipid DDAB $(0.2 \mathrm{~mol})$, which improved the incorporation of nucleic acid into the aqueous liposome center. A smaller 
quantity of DSPE-PEG $2000(0.6 \mathrm{~mol})$ and DSPE-PEG 2000 -maleimide $(30 \mathrm{nmol})$ provided steric properties, and the maleimide group allowed the addition of thiolated transferrin.

Transferrin receptor and WT1 expression in the Bl6F10 cell line. B16F10 cells showed $87 \%$ positivity for the Tf receptor according to flow cytometry results (Fig. 2A). In addition, western blotting confirmed expression of WT1 in B16F10 cells (Fig. 2B). Thus, B16F10 cells were selected as a suitable model to test Tf-conjugated PEG liposomes loaded with WTI shRNA.

In vivo assay. Administration of different treatments $\mathrm{Lip}+\mathrm{RNAi}$ + Tf, Lip + RNAi, Lip + GFP + Tf and untreated was initiated four days after cells were injected subcutaneously into mice. Treatments were administered six times through intravenous tail vein injection during a period of five days.

The mean percentage of weights of mice previously inoculated with B16F10 cells and treated with Lip + RNAi + Tf, Lip + RNAi, Lip + GFP + Tf and untreated is shown in Fig. 3A. Untreated and Lip + RNAi + Tf groups showed increases of $34 \%(\mathrm{SD} \pm 24.92)$ and $41 \%(\mathrm{SD} \pm 12.78)$ respectively, without significant differences between groups. In Lip + RNAi and Lip + GFP + Tf groups showed a low increase of $1.5 \%$ $(\mathrm{SD} \pm 12.97)$ and $10 \%(\mathrm{SD} \pm 6.87)$ respectively, against final reading on day 19 .

Fig. 3B we found that Lip + RNAi and Lip + GFP + Tf groups grew, and there was a decrease in survival. For this reason, we were only able to record measurements to day 19 post-implant. The Lip + RNAi + Tf treatment showed a significant decrease $(\mathrm{P}<0.05)$ in tumor volume compared to the untreated group. The final readings presented a mean of $7,871 \mathrm{~mm}^{3}(\mathrm{SD} \pm 2,087)$ for the untreated group and $5,981 \mathrm{~mm}^{3}$ $(\mathrm{SD} \pm 2,099)$ for Lip + RNAi + Tf group. This change represents a reduction in tumor volume of $24 \%$.

Fig. $3 \mathrm{C}$ shows the mean final tumors weight of the groups of mice sacrificed at the end of the trial. Only the untreated and Lip + RNAi + Tf groups were analyzed because the mice of the other groups died after day 30 . The results showed a reduction in tumor mass in the Lip + RNAi + Tf group and a mean tumor weight of $5.5 \mathrm{~g}(\mathrm{SD} \pm 0.87)$ compared with the untreated group that showed to mean tumor weight of $8.8 \mathrm{~g}$ $(\mathrm{SD} \pm 0.30)$. The decrease of $34 \%$ in weight of the tumors collected shows that tumor size was significantly reduced $(\mathrm{P}<0.05)$ in Lip + RNAi + Tf group.

Fig. 3D the survival rate of C57BL/6 mice with implanted B16F10 melanoma cells subcutaneously into the right thigh of the hind limb was 25.22 days $(\mathrm{SD} \pm 1.31)$. The untreated group presented a survival rate of $22.2 \%$ and Lip + RNAi + Tf group showed a survival rate of $62.5 \%$, equivalent to an increase of $37 \%$. This difference suggests that treatment with Lip + RNAi + Tf significantly increases survival in melanoma model employed $(\mathrm{P}<0.060)$. The Lip + RNAi and Lip + GFP + Tf groups showed a reduced survival compared to the untreated group, with a mean survival estimated at 20.25 and 17.75 days, respectively. The surviving mice were sacrificed on day 30 for humane reasons (+ Censored groups).

Analysis of WT1 expression in mouse tumor tissues. The WTI expression levels in all groups of mice were analyzed using
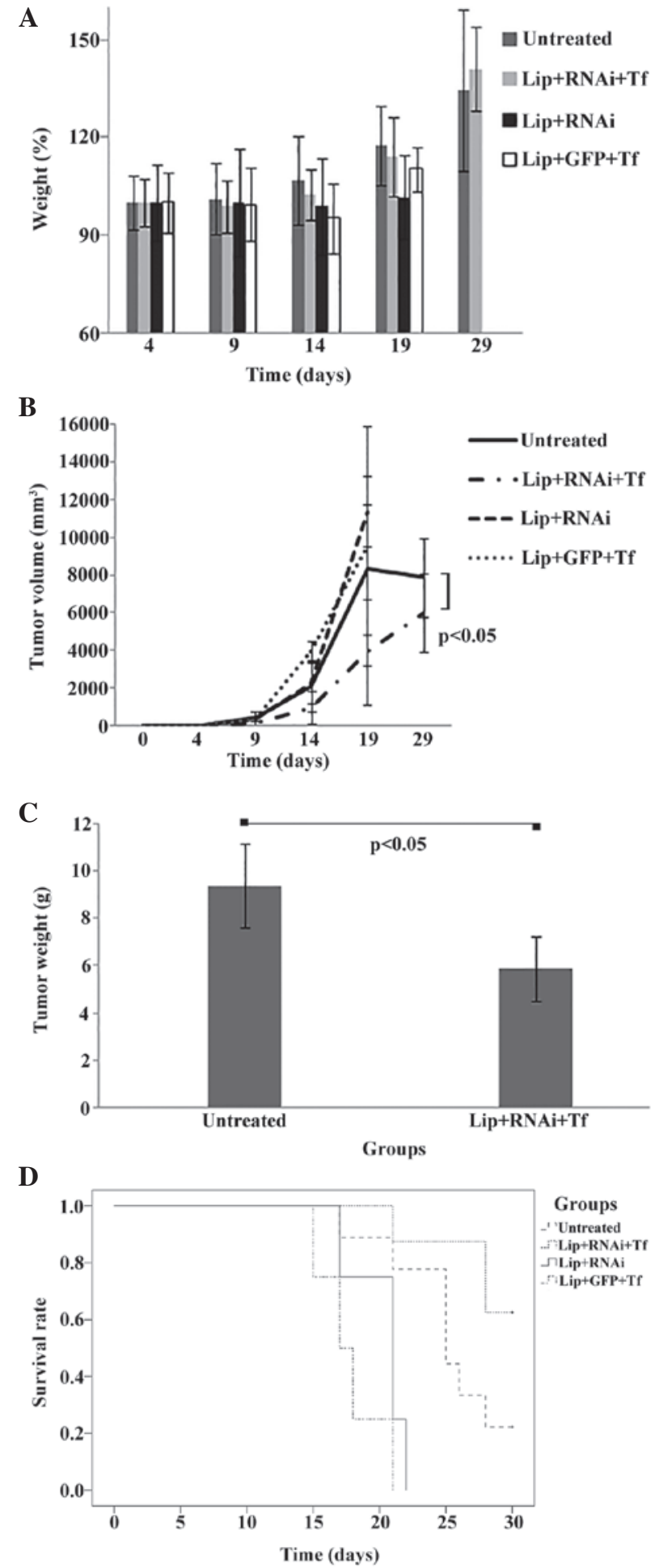

Figure 3. Antitumor activity of treatments in model in vivo. (A) Analysis of body weight of 'in vivo' assay. Mean percentages of the total weight of mice groups (untreated, Lip + RNAi + Tf, Lip + RNAi and Lip + GFP + Tf) during the time (days) of assay. Not significant difference was observed between groups. (B) Analysis of tumor volume in vivo assay. B16f10 cells were implanted subcutaneously into C57BL/6 mice. Intravenous injection of $\mathrm{Lip}+\mathrm{RNAi}+\mathrm{Tf}, \mathrm{Lip}+\mathrm{RNAi}, \mathrm{Lip}+\mathrm{GFP}+\mathrm{Tf}$ and untreated treatments were performed. Data are expressed as the mean \pm standard deviation (SD). Tumor volume was calculated using the following formula: Length $\mathrm{x}$ width ${ }^{2} \mathrm{x} 0.5$ and presented as $\mathrm{mm}^{3}$. (C) Analysis of tumor weight in vivo assay. The figure shows the weight mean of collected tumors in grams from groups untreated and Lip + RNAi + Tf. The standard deviation and statistical significance $(\mathrm{P}<0.05)$ were included. Data are expressed as mean including SD. (D) Analysis of rate survival in vivo assay. Kaplan-Meier curves of survival rate of mice groups. The assay was censored at 30 days after initial seeded of B16F10 cells (+). 


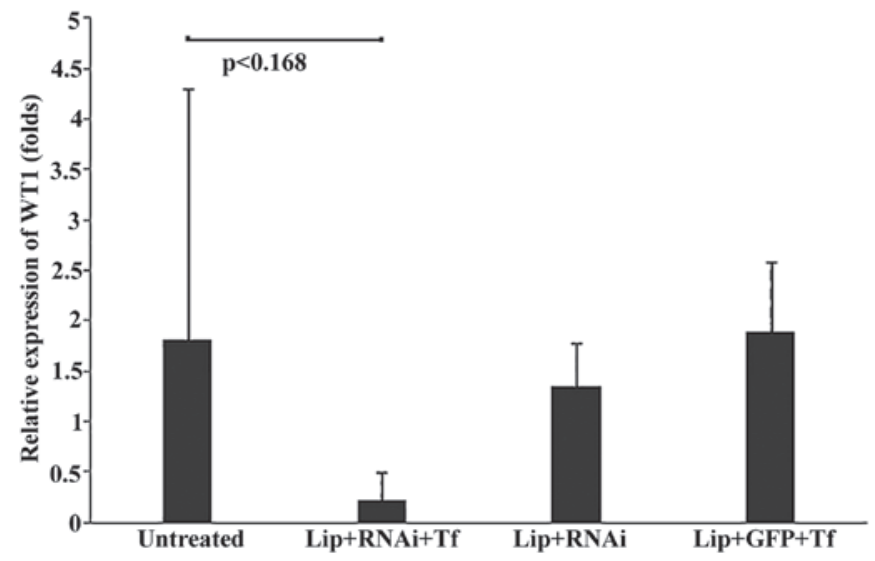

Figure 4. Analysis of WT1 expression in mouse tumor tissues. Figure presents the mean relative expression folds of WT1 in samples analyzed of the different groups of mice used in the in vivo model. Quantitative polymerase chain reactions were run in duplicate and $\beta$-actin was used as an endogenous gene. Data are expressed as the mean including standard deviation, and the statistical value were included in the graph $(\mathrm{P}<0.168)$.

RT-qPCR analysis. The samples analyzed of Lip + RNAi and Lip + GFP + Tf groups were extracted soon after death of the mouse. In Fig. 4 show the relative expression of WT1 standardized according to the Livak method. To accomplish this, the average obtained from samples of untreated group was established as a calibrator and $\beta$-actin was used as endogenous control. Fig. 4 shows that the Lip + RNAi + Tf group showed a mean relative expression level of $0.21(\mathrm{SD} \pm 0.28)$-fold, representing a decrease in expression of WT1, compared with the other groups of mice which presented mean relative expression levels of $1.8(\mathrm{SD} \pm 2.49)$-fold for the untreated group of mice, 1.34 ( $\mathrm{SD} \pm 0.43$ )-fold for the Lip + RNAi group, and 1.89 $(\mathrm{SD} \pm 0.69)$-fold for the Lip $+\mathrm{GFP}+\mathrm{Tf}$ group. The reduction in the expression levels of WTI in the Lip + RNAi + Tf group suggests that tumor samples decrease in the expression of WT, which in turn suggests internalization directed by Tf.

\section{Discussion}

During the last three decades, global incidence of melanoma has rapidly increased, particularly among Caucasian populations (3). The increased mortality rate from melanoma is associated with a relatively late-stage diagnosis and resistance to chemotherapeutic agents (3).

The search for new therapeutic strategies has helped identify new tumor-specific molecules suitable for gene therapy (9). Restoration of tumor suppressor genes, such as $p 53$, is a major strategy used for tumor reduction (43). Antisense and RNA interference are additional strategies for targeting genes involved in cancer. Well-defined tumor markers in melanoma include mutations in the oncogenes $N R A S, B R A F, c-K I T, G N A Q$ and GNA11 or reduced function of the tumor suppressor genes PTEN and p53 (44-48). Between 40 and $60 \%$ of melanomas exhibit mutations in $B R A F$, and $90 \%$ have mutations in $p 53$, although only $10 \%$ of these mutations actually disable the tumor suppressor activity of p53 (49). Recent studies show high expression of wild-type WT1 in a large proportion of solid and non-solid tumors, including melanoma (13-16,50). WT1 is a multifaceted protein involved in cell proliferation, cell death and angiogenesis. WT1 expression is found in 39\% of melanomas, and $>80 \%$ of WT1-positive melanomas is diagnosed in advanced stages of the disease. Thus, WT1 is a potential therapeutic target in melanoma. Antisense oligonucleotide and RNA interference strategies that decrease the expression of WT1 decreased the proliferation of cancer cells (51-54).

One of the limitations of gene therapy is tumor-specific delivery. The use of viral vectors is a good method for delivering genetic material in vitro (46-48); this strategy is limited by the host immune response in vivo (55-57).

The main advantages of liposomes include considerable concentration of large quantities of antitumor agent and intracellular delivery, increased half-life of tumor agents due to reduced degradation, gradual delivery of antineoplastic molecules, easy removal and reduced toxicity (24).

Phospholipid derivatives are currently used to improve circulating of liposomes and reduce their elimination by the liver and macrophages (58). The incorporation of thiol groups allows crosslinking with lysines in proteins, which can yield liposomes targeted to the ligand-receptor. The Tf receptor is widely used as delivery vehicle targeting tumor cells (41). The Tf receptor, CD71, is involved in the intracellular uptake of iron. The high expression of CD71 in many tumors, including melanoma, and the association with high iron requirements by dividing cells, makes this a good target (59). Tf is a serum protein found in high concentrations in the blood and is the natural ligand for the Tf receptor. Due to the versatility of the Tf receptor, it is useful for the delivery of transferrin antitumor agents, such as toxins, proteins and genetic materials $(28,29,32,33,40)$.

In a previous study, we demonstrated the ability of shRNA to silence the WT1 gene and induce apoptosis in B16F10 murine melanoma cells (41). In a model of lung metastasis, application of this shRNA via aerosol was successful in reducing the size and number of tumors (60). The delivery system was effectively applied using PEI-DNA complexes, which reached high concentrations in the lung; however, this form application works exclusively in the lung (60). Systemic application of targeted liposomes opens the possibility of targeting WT1 in tumors in other parts of body (60). Liposome therapy would not be exclusive for melanoma, as other types of tumors express WT1 and the Tf receptor. The present results showed a $24 \%$ decrease in tumor size without changes in body weight. The final weight of the tumor for the experimental group differed by $34 \%$ from that of the control mice (20). In addition, an improvement in survival of $37 \%$ was observed in mice treated with Tf-conjugated PEG liposomes loaded with WT1 shRNA. These are important results, considering that $\mathrm{B} 16 \mathrm{~F} 10$ cells form very aggressive tumors in C57BL/6 mice (14).

A reduction in WT1 expression was noted in the Lip + RNAi + Tf experimental treatment group. Although transfection efficiency was not analyzed, RT-qPCR suggests that decreased expression of WT1 was associated with a reduction in tumor mass. Tumors were collected within $24 \mathrm{~h}$ of the last treatment. In order to identify transfected cells with decreased expression of WT1, we would have to assess expression of beta-galactosidase about 2-6 h after in vivo inoculation (41). 
Complete tumor eradication was not possible; thus, further studies should examine increased concentrations of liposome complexes or additional anticancer molecules. Previous studies have shown that WT1 silencing sensitizes cells to chemotherapeutic agents, such as cisplatin, doxorubicin and radiation. Increased sensitivity to apoptotic stimuli in response to silencing of WT1 is likely due to the fact that WT1 regulates $\mathrm{Bcl}-2$, multi-drug resistance 1 (MDR1) and P-glycoprotein expression, which are involved in chemoresistance $(21,61,62)$.

\section{Acknowledgements}

This study was supported by the Microbiology and immunology Department, Biological Sciences Faculty, Autonomous University of Nuevo León (UANL).

\section{References}

1. Cichorek M, Wachulska M, Stasiewicz A and Tymińska A Skin melanocytes: Biology and development. Postepy Dermatol Alergol 30: 30-41, 2013.

2. Situm M, Buljan M, Bulić SO and Simić D: The mechanisms of UV radiation in the development of malignant melanoma. Coll Antropol 31 (Suppl 1): 13-16, 2007.

3. Nikolaou V and Stratigos AJ: Emerging trends in the epidemiology of melanoma. Br J Dermatol 170: 11-19, 2014.

4. Leiter U, Buettner PG, Eigentler TK and Garbe C: Prognostic factors of thin cutaneous melanoma: An analysis of the central malignant melanoma registry of the german dermatological society. J Clin Oncol 22: 3660-3667, 2004.

5. Leiter U, Meier F, Schittek B and Garbe C: The natural course of cutaneous melanoma. J Surg Oncol 86: 172-178, 2004.

6. Lee ML, Tomsu K and Von Eschen KB: Duration of survival for disseminated malignant melanoma: Results of a meta-analysis. Melanoma Res 10: 81-92, 2000.

7. Hewitt SM, Hamada S, McDonnell TJ, Rauscher FJ III and Saunders GF: Regulation of the proto-oncogenes bcl-2 and c-myc by the Wilms' tumor suppressor gene WT1. Cancer Res 55: 5386-5389, 1995.

8. Englert C, Hou X, Maheswaran S, Bennett P, Ngwu C, Re GG, Garvin AJ, Rosner MR and Haber DA: WT1 suppresses synthesis of the epidermal growth factor receptor and induces apoptosis. EMBO J 14: 4662-4675, 1995.

9. Maheswaran S, Englert C, Bennett P, Heinrich G and Haber DA: The WT1 gene product stabilizes p53 and inhibits p53-mediated apoptosis. Genes Dev 9: 2143-2156, 1995.

10. Haber DA, Englert C and Maheswaran S: Functional properties of WT1. Med Pediatr Oncol 27: 453-455, 1996.

11. Englert C, Maheswaran S, Garvin AJ, Kreidberg J and Haber DA: Induction of p21 by the Wilms' tumor suppressor gene WT1. Cancer Res 57: 1429-1434, 1997.

12. Scholz H and Kirschner KM: A role for the Wilms' tumor Protein WT1 in organ development. Physiology (Bethesda) 20: 54-59, 2005 .

13. Oji Y, Miyoshi S, Maeda H, Hayashi S, Tamaki H, Nakatsuka S, Yao M, TakahashiE, Nakano Y, Hirabayashi H, et al: Overexpression of the Wilms' tumor gene WT1 in de novo lung cancers. Int J Cancer 100: 297-303, 2002.

14. Loeb DM, Evron E, Patel CB, Sharma PM, Niranjan B Buluwela L, Weitzman SA,Korz D and Sukumar S: Wilms tumor suppressor gene (WT1) is expressed inprimary breast tumors despite tumor-specific promoter methylation. Cancer Res 61: 921-925, 2001.

15. Miyoshi Y, Ando A, Egawa C, Taguchi T, Tamaki Y, Tamaki H, Sugiyama H and Noguchi S: High expression of Wilms' tumor suppressor gene predicts poor prognosis in breast cancer patients. Clin Cancer Res 8: 1167-1171, 2002.

16. Oji Y, Miyoshi Y, Koga S, Nakano Y, Ando A, Nakatsuka S, Ikeba A, Takahashi E,Sakaguchi N, Yokota A, et al: Overexpression of the Wilms' tumor gene WT1 in primary thyroid cancer. Cancer Sci 94: 606-611, 2003.

17. Wagner N, Panelos J, Massi D and Wagner KD: The Wilms' tumor suppressor WT1 is associated with melanoma proliferation. Pflugers Arch 455: 839-847, 2008.
18. Garrido-Ruiz MC, Rodriguez-Pinilla SM, Pérez-Gómez B and Rodriguez-Peralto JL: WT 1 expression in nevi and melanomas: A marker of melanocytic invasion into the dermis. J Cutan Pathol 37: 542-548, 2010.

19. Wilsher M and Cheerala B: WT1 as a complementary marker of malignant melanoma: An immunohistochemical study of whole sections. Histopathology 51: 605-610, 2007.

20. Zamora-Avila DE, Franco-Molina MA, Trejo-Avila LM, Rodríguez-Padilla C, Reséndez-Pérez D and Zapata-Benavides P: RNAi silencing of the WT1 gene inhibits cell proliferation and induces apoptosis in the B16F10 murine melanoma cell line. Melanoma Res 17: 341-348, 2007.

21. Zapata-Benavides P, Manilla-Muñoz E, Zamora-Avila DE, Saavedra-Alonso S, Franco-Molina MA, Trejo-Avila LM, Davalos-Aranda $\mathrm{G}$ and Rodríguez-Padilla C: WT1 silencing by RNAi synergizes with chemotherapeutic agents and induces chemosensitization to doxorubicin and cisplatin in B16F10 murine melanoma cells. Oncol Lett 3: 751-755, 2012.

22. Yu KF, Zhang WQ, Luo LM, Song P, Li D, Du R, Ren W, Huang D, Lu WL, Zhang $X$ and Zhang Q: The antitumor activity of a doxorubicin loaded, iRGD-modified sterically-stabilized liposome on B16-F10 melanoma cells: In vitro and in vivo evaluation. Int J Nanomedicine 8: 2473-2485, 2013.

23. Maruyama K, Ishida O, Kasaoka S, Takizawa T, Utoguchi N, Shinohara A, Chiba M, Kobayashi H, Eriguchi M and Yanagie H: Intracellular targeting of sodium mercaptoundecahydrododecaborate $(\mathrm{BSH})$ to solid tumors by transferrin-PEG liposomes, for boron neutron-capture therapy (BNCT). J Control Release 98: 195-207, 2004.

24. Torchilin V: Tumor delivery of macromolecular drugs based on the EPR effect. Adv Drug Deliv Rev 63: 131-135, 2011.

25. Boerman OC, Oyen WJ, van Bloois L, Koenders EB, van der Meer JW, Corstens FH and Storm G: Optimization of technetium-99m-labeled PEG liposomes to image focal infection: Effects of particle size and circulation time. J Nucl Med 38: 489-493, 1997.

26. Derycke AS and De Witte PA: Transferrin-mediated targeting of hypericin embedded in sterically stabilized PEG-liposomes. Int J Oncol 20: 181-187, 2002.

27. Papahadjopoulos D, Allen TM, Gabizon A, Mayhew E, Matthay K, Huang SK, Lee KD, Woodle MC, Lasic DD, Redemann C, et al: Sterically stabilized liposomes: Improvements in pharmacokinetics and antitumor therapeutic efficacy. Proc Natl Acad Sci USA 88: 11460-11464, 1991.

28. Stavridis JC, Deliconstantinos G, Psallidopoulos MC, Armenakas NA, Hadjiminas DJ and Hadjiminas J: Construction of transferrin-coated liposomes for in vivo transport of exogenous DNA to bone marrow erythroblasts in rabbits. Exp Cell Res 164: 568-572, 1986.

29. Vidal M, Sainte-Marie J, Philippot JR and Bienvenue A: The influence of coupling transferrin to liposomes or minibeads on its uptake and fate in leukemic L2C cells. FEBS Lett 216: 159-163, 1987.

30. Di Giulio A, D'Andrea G, Saletti MA, Impagnatiello A, D'Alessandro AM and Oratore A: The binding of human serum transferrin to its specific receptor reconstituted into liposomes. Cell Signal 6: 83-90, 1994.

31. Egea MA, García ML, Alsina MA and Reig F: Coating of liposomes with transferrin: Physicochemical study of the transferrin-lipid system. J Pharm Sci 83: 169-173, 1994.

32. Corley $\mathrm{P}$ and Loughrey HC: Targeting of doxorubicin loaded liposomes to T-cells via the transferrin receptor. Biochem Soc Trans 26: S37, 1998.

33. Simões S, Slepushkin V, Gaspar R, de Lima MC and Düzgüneş N: Gene delivery by negatively charged ternary complexes of DNA, cationic liposomes and transferrin or fusigenic peptides. Gene Ther 5: 955-964, 1998.

34. Singh M: Transferrin as a targeting ligand for liposomes and anticancer drugs. Curr Pharm Des 5: 443-451, 1999.

35. Eavarone DA, Yu X and Bellamkonda RV: Targeted drug delivery to C6 glioma by transferrin-coupled liposomes. J Biomed Mater Res 51: 10-14, 2000.

36. Ishida O, Maruyama K, Tanahashi H, Iwatsuru M, Sasaki K, Eriguchi $M$ and Yanagie H: Liposomes bearing polyethyleneglycol-coupled transferrin with intracellular targeting property to the solid tumors in vivo. Pharm Res 18: 1042-1048, 2001.

37. Voinea M, Dragomir E, Manduteanu I and Simionescu M: Binding and uptake of transferrin-bound liposomes targeted to transferrin receptors of endothelial cells. Vascul Pharmacol 39: 13-20, 2002. 
38. Anabousi S, Laue M, Lehr CM, Bakowsky U and Ehrhardt C: Assessing transferrin modification of liposomes by atomic force microscopy and transmission electron microscopy. Eur J Pharm Biopharm 60: 295-303, 2005.

39. Sharma G, Modgil A, Layek B, Arora K, Sun C, Law B and Singh J: Cell penetrating peptide tethered bi-ligand liposomes for delivery to brain in vivo: Biodistribution and transfection J Control Release 167: 1-10, 2013.

40. Kobayashi T, Ishida T, Okada Y, Ise S, Harashima H and Kiwada H: Effect of transferrin receptor-targeted liposomal doxorubicin in P-glycoprotein-mediated drug resistant tumor cells. Int J Pharm 329: 94-102, 2007.

41. Shi $\mathrm{N}$ and Pardridge WM: Noninvasive gene targeting to the brain. Proc Natl Acad Sci USA 97: 7567-7572, 2000.

42. Livak KJ and Schmittgen TD: Analysis of relative gene expression data using real-time quantitative PCR and the 2(-Delta Delta C (T)) Method. Methods 25: 402-418, 2001.

43. Xu L, Pirollo KF and Chang EH: Tumor-targeted p53-gene therapy enhances the efficacy of conventional chemo/radiotherapy. J Control Release 74: 115-128, 2001

44. Carlino MS, Haydu LE, Kakavand H, Menzies AM,Hamilton AL, Yu B, Ng CC, Cooper WA, Thompson JF, Kefford RF, et al: Correlation of BRAF and NRAS mutation status with outcome, site of distant metastasis and response to chemotherapy in metastatic melanoma. Br J Cancer 111: 292-299, 2014

45. Pilloni L, Bianco P, Difelice E, Cabras S, Castellanos ME, Atzori L, Ferreli C, Mulas P, Nemolato S and Faa G: The usefulness of c-Kit in the immunohistochemical assessment of melanocytic lesions. Eur J Histochem 55: 105-111, 2011.

46. Khalili JS, Yu X, Wang J, Hayes BC, Davies MA, Lizee G, Esmaeli B and Woodman SE: Combination small molecule MEK and PI3K inhibition enhances uveal melanoma cell death in a mutant GNAQ and GNA11 dependent manner. Clin Cancer Res 18: 4345-4355, 2012.

47. Zhou X-P, Gimm O, Hampel H, Niemann T, Walker MJ and Eng C: Epigenetic PTEN silencing in Malignant Melanomas without PTEN Mutation. Am J Pathol 157: 1123-1129, 2000.

48. Terzian T, Torchia EC, Dai D, Robinson SE, Murao K, Stiegmann RA, Gonzalez V,Boyle GM, Powell MB, Pollock PM, et al: $\mathrm{p} 53$ prevents progression of nevi to melanoma predominantly through cellcycle regulation. Pigment Cell Melanoma Res 23: 781-794, 2010.

49. Box NF, Vukmer TO, and Terzian T: Targeting p53 in melanoma Pigment Cell Melanoma Res 27: 8-10, 2014

50. Miyagi T, Ahuja H, Kubota T, Kubonishi I, Koeffler HP and Miyoshi I: Expression of the candidate Wilm's tumor gene, WT1, in human leukemia cells. Leukemia 7: 970-977, 1993.

51. Zapata-Benavides P, Tuna M, Lopez-Berestein G and Tari AM: Downregulation of Wilms' tumor 1 protein inhibits breast cancer proliferation. Biochem Biophys Res Commun 295: 784-790, 2002.
52. Chen MY, Clark AJ, Chan DC, Ware JL, Holt SE, Chidambaram A, Fillmore HL and Broaddus WC: Wilms' tumor 1 silencing decreases the viability and chemoresistance of glioblastoma cells in vitro: A potential role for IGF-1R de-repression. J Neurooncol 103: 87-102, 2011.

53. Huo X, Ren L, Shang L, Wang X and Wang J: Effect of WT1 antisense mRNA on the induction of apoptosis in ovarian carcinoma SKOV3 cells. Eur J Gynaecol Oncol 32: 651-656, 2011.

54. Chen Y, Bathula SR, Yang Q and Huang L: Targeted nanoparticles deliver siRNA to melanoma. J Invest Dermatol 130: 2790-2798, 2010.

55. Zhang X, Jin Y, Zhang B and Chen H: Preparation of recombinant adenovirus Ad5/F35 containing human WT1 and identification after recombinant adenovirus infected dendritic cells. Xi Bao Yu Fen Zi Mian Yi Xue Za Zhi 30: 135-138, 2014 (In Chinese)

56. Sundarasetty BS, Singh VK, Salguero G, Geffers R, Rickmann M, Macke L, Borchers S, Figueiredo C, Schambach A, Gullberg U, et al: Lentivirus-induced dendritic cells for immunization against high-risk WT1(+) acute myeloid leukemia. Hum Gene Ther 24: 220-237, 2013.

57. Shan XY, Liu ZL, Wang B, Guo GX, Wang MS, Zhuang FL, Cai CS, Zhang MF and Zhang YD: Construction of recombinant lentiviral vector of Tie2-RNAi and its influence on malignant melanoma cells in vitro. Zhonghua Zheng Xing Wai Ke Za Zhi 27: 277-283, 2011 (In Chinese).

58. Drummond DC, Meyer O, Hong K, Kirpotin DB and Papahadjopoulos D: Optimizing liposomes for delivery of chemotherapeutic agents to solid tumors. Pharmacol Rev 51: 691-743, 1999.

59. Cheever MA, Allison JP, Ferris AS, Finn OJ, Hastings BM, Hecht TT, Mellman I, Prindiville SA, Viner JL, Weiner LM and Matrisian LM: The prioritization of cancer antigen: A national cancer institute pilot project for the acceleration of translational research. Clin Cancer Res 15: 5323-5337, 2009.

60. Zamora-Avila DE, Zapata-Benavides P, Franco-Molina MA, Saavedra-Alonso S, Trejo-Avila LM, Reséndez-Pérez D, Méndez-Vázquez JL, Isaias-Badillo J and Rodríguez-Padilla C: WT1 gene silencing by aerosol delivery of PEI:RNAi complexes inhibits B16-F10 lung metastases growth. Cancer Gene Ther 16: 892-899, 2009

61. Clark AJ, Chan DC, Chen MY, Fillmore H, Dos Santos WG, Van Meter TE, Graf MR and Broaddus WC: Down-regulation of Wilms' tumor 1 expression in glioblastoma cells increases radiosensitivity independently of p53. J Neurooncol 83: 163-172, 2007.

62. Shen H, Xu W, Wu Z, Tang H, Xie Y and Zhong X: Down-regulation of WT1/+17AA gene expression using RNAi and modulating leukemia cell chemotherapy resistance. Haematologica 92: 1270-1272, 2007. 